\title{
Liminaalsed perioodid udmurdi rahvakalendris
}

\begin{abstract}
Aado Lintrop
Teesid: Talvise ja suvise pööripäeva järgsed ajavahemikud moodustavad udmurdi rahvakalendris omaette liminaalsed perioodid, mida iseloomustavad ranged käitumiseeskirjad ja mitmesuguste tööde tegemise keelud. Mõlemate perioodide nimed tulenevad liminaalsust või vahepealset tähistanud sõnast. Need perioodid erinevad oluliselt kevadise ja sügisese pööripäevaga seotud pühadest - nad on märkimisväärsel määral seotud veega, nende ajal ei tohi valjusti laulda ega käratseda. Neist erinevalt pole sügisene ega kevadine pööriaeg välja venitatud pikaks üleminekuperioodiks, vaid on markeeritud konkreetsete kalendritähtpäevadega, mis on ühtlasi talvise ja kevadise poolaasta alguspunktideks. Tõenäoliselt oli suvine liminaalne periood algselt pühendatud taevale ja talvine liminaalne periood allilmale.
\end{abstract}

Märksõnad: liminaalsus, pööripäev, rahvakalender, rahvausund, udmurdid

\section{Pühad ajad}

Oma kultuuriruumis oleme harjunud aega kujutama lineaarsena ja nägema ennast eluteel rändajatena, kes paraku ei saa tuldud teed mööda tagasi minna. Nagu iga rännak, koosneb ka ajamatk erinevatest teelõikudest ja läbikäidud rada tähistavatest märkidest. Nagu maastikul, nii pole need ajaski üheväärsed. Mõni verstapost tundub olevat olulisem, mõni teeäärne puhkepaik näib meeldivam või tähenduslikum. Tähistame ja pühitseme neid, mõtleme välja toimingud ühe etapi lõpetamise ja teise alustamise tarvis. Erilised paigad nõuavad erilist käitumist nii ruumis kui ka ajas. Samas on elutee lineaarne aeg liigendatud Maa tiirlemisest ja pöörlemisest tingitud korduvate rütmidega. Ka need pole inimesele võrdsed, vaid omavad erinevaid tähendusi ja väärtusi. Ka nende vahel on üleminekud, mida mõtestatakse erilistena ja mis seetõttu nõuavad ka teistsugust käi-

http://haldjas.folklore.ee/tagused/nr32/lintrop.pdf 
tumist. Ööpäeva siirdehetked on kesköö ja keskpäev, aasta siirdeajad on talvine ja suvine pööripäev ning kevadine ja sügisene võrdpäevsus. Olulised on ka elatusaladega seotud üleminekuperioodid - talviste tubaste tööde järel kevadiste põllutööde alustamise aeg, jahi- või kalapüügihooaja algus, talvisest elupaigast suvisesse kolimine.

Võime öelda, et inimeste elud ja kalendriaastad sisaldavad vaheaegu, mida iseloomustab argipäevaste piiride puudumise tõttu määramatus või piirideta olek. Need ajad on avatud nii heale kui ka kurjale ning on lähedal üleloomulikule. Piirid on osa meie orienteerumissüsteemist. Ilma nendeta oleks ruum homogeenne, poleks vahet omade ja võõraste, heade ja halbade, pühade ja profaansete paikade vahel. Samuti on lugu ajaga. Väljendid hea aeg, halb aeg, raske aeg, hull aeg, kiire aeg, pühadeaeg, argiaeg, lapsepõlv, noorus, meheiga jne sisaldavad ilmselgeid hinnanguid ja piiritõmbamisi. Üleminekud ühest ajast, ühest eluetapist, ühest staatusest teise on omamoodi ristteed või teelahkmed ajas. Teame mitmete rahvaste mütoloogia põhjal, et risttee on liminaalne paik, kus kogunevad rahutud või kodutud vaimud ja kus võib sooritada maagilisi toiminguid (Puhvel 1989). Kui liminaalsus muudab tavaorientatsiooni mittetoimivaks, osutub ka tavaline käitumine ebaotstarbekaks või ebasobivaks. Erilised ajad nõuavad erilist käitumist. Seepärast on inimene aegade jooksul praktiseerinud mitmesuguseid liminaalsete seisundite ja aegadega seotud toiminguid, mida analüütiliselt nimetatakse siirderiitusteks.

\section{Liminaalne aeg udmurdi rahvakalendris}

Udmurdi rahvakalendris on kaks peamist üleminekuperioodi: aega pärast talvist pööripäeva kutsutakse vožodỉr (vožo-aeg) või uivožo (öövožo) ja aega pärast suvist pööripäeva invožo dịr (taevase vožo aeg) või vožo poton tolez (vožo ilmumise kuu).

Vanapermi veža oli sõna, mis oma semantilise välja poolest lubas kasutuselevõtmist kristliku mõiste 'püha' vastena: йен Вэжa лоb-püha vaim, Вэжa куил $и a$ - püha kolmainsus, Beжa ıyH-pühapäev (Lõtkin 1952: 156). Tänapäeva komi keeles on veža samuti 'püha': veža va - püha (pühitsetud) vesi, vežai - ristiisa (püha isa), vežan - ristiema. Vežadir on jõuluaeg (vene свяmкu). Kuid sürjakomi veža tähenduseks on ka 'roojane' ja 'kurat' (Gribova 1975: 110). Verb vežni tähendab 'vahetama', vežöm on komi mütoloogias kuradi või kurja vaimu poolt äravahetatud laps. Udmurdi keeles pole sõnal vožo otsest tähendust 'püha', see ilmneb ainult seoses jõuluajaga, mida udmurdid sarnaselt komidele nimetavad vožodirr. Ent udmurtidel on nimetus ka selle suvise vaste kohta - invožo 
dịr (taevas+vožo+aeg). Vožod on vetehaldjaga seostuvad kuradisarnased vaimud (vt Lintrop 2004: 8-11).

Ilmselt lähtub permi veža/vožo soome-ugri sõnatüvest, mis märkis liminaalsust või kusagil vahepeal olemist: *vaješ > algpermi vež- > udmurdi vož 'risttee, jõesuu, emb-kumb kahest lõimereast, lõimelõngade ristumine', vrd vožen-vožen 'vaheldumisi', vožmin 'kordamööda', võib-olla ka invož (taevas+vož) 'silmapiir'; komi vež, viž - tui-vež 'risttee', vežni 'vahetama'; soome vaihe, eesti vahe (SKES 5: 1592-1593).

Soome lingvistid ainult oletasid seoseid soome vaihe ja permi vež- vahel. Kui nad oleksid paremini tundnud udmurdi või komi mütoloogiat, oleksid nad olnud kindlad. Komi liitsõnas vežadị ja selle udmurdi paralleelis vožodịr märgib esimene komponent nimelt liminaalsust, pööriaega, kahe tavalise perioodi vahele jäävat ebatavalist aega.

Nii suvise kui ka talvise vožo-aja kohta käis rida keelde. 19. sajandi vene teadlane Nikolai Pervuhhin kirjutas:

Praegusel ajal on Glazovi maakonna votjakkidel säilinud vaid uskumus, et vožo-ajal ei tohi teha kära, eriti aga lärmata vee lähedal, mistôttu suvel ei ujuta, ei mängita vee ääres ringmänge ega pesta pesu. Talvel ei pesta jões pesu ja kardetakse lauldes üle silla sõita. Samuti ei tohi talvel sel ajal jalgadega hõõguvaid süsi, mis näiteks peeru otsast kukuvad, surnuks trampida... Gõja, Lõpi ja Polomi vallas seostus vožo-aeg rukki õitsemisega. ${ }^{1}$ Eriliseks patuks loeti sel ajal vee reostamist, mistõttu ei tohtinud mitte ainult ujuda, pesu või nõusid pesta (ka kaevu juures), vaid isegi karja jõkke ajada. Eriti tuli keelde pidada keskpäeva paiku, kui pü̈̈ti valju häält üldse mitte teha (Pervuhhin 1888a: 59-60).

Soome uurija Uno Harva teatab, et keelust üleastumise pärast kannatas terve kogukond - tagajärjeks olnud torm või rahesadu (Holmberg 1914: 174). Kuzebajevo naised rääkisid, et suvisel invožo-ajal ei tohtinud töötada villa ega kanepiga, samuti oli keelatud niitmine ja lillede noppimine. Kuzebajevos lõpeb see periood peetripäeval (12. juulil) peetavate palvuste-ohvritoomistega suures palvekojas (bíd'dźím kuala) ja ohvrihiies (lud). Järgmisel päeval algab heinaaeg. Sageli seostatakse invožo-perioodi punase pusurohu (invožo śaśka) õitsemisajaga. Juunis 2003 ütlesid mõned Tatarstani Agrõzi rajooni Varklet-Bodja küla inimesed: vöś, pe, voź víle pote invožo dírja (öeldakse, et invožo-ajal kõnnib palve (või usk) ${ }^{2}$ mööda niitu).

Meie kontekstis olulise tähelepaneku on teinud udmurdi folklorist Irina Nurijeva, kes väidab, et erinevalt kevadistest ja sügisestest pühadest välistab talviste ja suviste pööriaegade akustiline kood valjuhäälse rituaalse laulmise (Nurijeva 2004: 74). 
Talvine vožo-aeg oli udmurtidel peamine jutustamise ja mõistatamise aeg (Škljajev 1989: 36). Muuseas väitsid kolm Krasnogorskoje rajooni Udmurt Karauli ja Djobõ külades elavat informanti veel 2002. aasta juunis, et mõistatus on kohalikus dialektis vožo kill (vožo keel, sõna või jutt) või vožo mad' (vožo kõne, sõna või jutt). ${ }^{3}$ Kuigi juba Nikolai Pervuhhin oletas, et mõistet vožo mad' võib tõlgendada kui talvise vožo valitsemisaja juttu (Pervuhhin 1888c: 70) ning sama meelt paistab olevat ka Tatjana Vladõkina (1998: 11), ei tundu selline interpretatsioon põhjendatud olevat. Ühest küljest viitas vožo mad' esivanemate kaudu teksti traditsioonilisusele (vrd vižž kill 'muistend: juur, sugu, sugukond, põlv või põlvkond + keel, sõna või jutt'), teiselt poolt aga näis siiski mõista andvat, et eksisteeris eriline keel pööriaja külalistega suhtlemiseks - muinasjuttude ja mõistatuste kunstipärane keel. Mõistatuste vožodega seostamise kasuks räägib ka see, et pärast talvist pööriaega oli mõistatamine keelatud: jö vile sulton bere madiśkinin ug jara: pudo vera kare 'pärast epifaaniat ${ }^{4}$ ei tohi mõistatada: lehmade udarad täituvad piimaga' (Vladõkina 1998: 73).

\section{Pööriaja külalised}

Glazovi maakonna udmurdid uskusid isegi 19. sajandi lõpul, et enne jõule tulevad vetehaldjad küladesse, kus elavad saunades. Hämaral ajal võib neid koguni tänaval kohata:

Suvisel vožo-ajal ta magab, aga talvisel tuleb veest välja (enne jõule) maa peale ja saadab suurema osa ajast mööda saunades, kuigi võib ka tänaval vastu tulla. Seepärast ei julge votjak jõulude ajal üksi ja ilma põletatud peerutükita tänaval käia (Pervuhhin 1888a: 75).

Jõuluaegseid vetehaldjaid kutsutigi vožodeks. N. Pervuhhin jätkab:

25. detsembrist 6. jaanuarini liiguvad külade, asulate ja isegi Glazovi linna tänavail, väljakutel ja tagahoovides väikesed (kasvult mitte üle poole arssina) mitmevärvilised, kuid enam-vähem ühesuguse välimusega (saba ja sarvedega) kuradikesed. Venelased kutsuvad neid kulišiteks, votjakid vožodeks. Nagu vetehaldjad, nii pelgavad ka vožod väiksematki põletatud peerutükki. [---] Neile, kes kõnnivad ringi peerutükita, panevad vožod jala taha [---] sama sihiga muutuvad nad kord postiks, kord majanurgaks... Kord viivad nad mehe oma kodu asemel naabri tarre, kord sunnivad naist õhtul võóraid loomi oma õue ajama... (Pervuhhin 1888a: 99-100). 
Vožodir on udmurtidel sanditamise aeg. Kõige levinum nimetus sanditamise kohta on pörtmaśkon, vrd pörtmani 'muutma, moonutama, laimama'. Kasutatakse ka nimetusi peńdż́aśkon (vrd peń 'nõgi, tuhk', peńd'źinị 'tuhastuma, tuhaks põlema', seotud kõige levinuma maskeerimisviisi - näo tuha või söega määrimisega), vožojaśkon (vožotamine; mitmel pool on sante endid vožodeks nimetatud) ja čokmorskon. Viimane lähtub sõnast čokmor 'puunui' (vrd vene чек.иapı 'puunui, kurikas' < чеka 'kiil, vai') ja seostub santidele iseloomuliku tegevuse - keppidega vastu majanurki ja põrandaid tagumisega. Sel kombel peletati majast ja külast eemale kurje vaime ja haigusi (Vladõkin 1994: 227).

Udmurdi jõulusandid on kahestunud olemusega: ühelt poolt näitavad pahupidi pööratud rõivad, nõega määritud näod, meeste poolt naisterõivaste kandmine ja vastupidi, et tegemist on külalistega toopoolsest maailmast (kus universaalse ettekujutuse kohaselt on asjad vastupidi kui elavate juures). Ka see, et jõulusante usuti karjaõnne toovat, seostab neid esivanemate hingedega, kellest paljude rahvaste juures arvati eelkõige sõltuvat just kariloomade edenemine. Ja last not least - sante nimetati otsesõnu vožodeks, viimased aga olid kahtlemata seotud surnud esivanematega.

Samas esinesid udmurdi jõulusandid ka kurjade jõudude peletajatena. Vladimir Vladõkin nimetab uskumust, et sandid jooksid kisa-käraga mööda külatänavat, tagusid kaigastega vastu majanurki, tuppa tulles aga vastu põrandat, hirmutasid saunavaime (mun čokuźoos - Vladõkin 1994: 226-227). Eespool sai mainitud, et üsna levinud ettekujutuse kohaselt asusid saunadesse talvisel pööriajal elama vožod. Tegelikult puudubki selge vahe saunahaldja ja vožo vahel. Tõenäoliselt on udmurdi jõulusantide kui eksortsistide tegevus lähtunud pööriaja lõpuga seotud kombestikust. Nimelt lõpeb talvine vožo-aeg 6. jaanuaril (õigeusu kirikukalendri järgi Jeesuse ristimise päeval) pühaga, mis udmurtidel kandis nimetust vožo kel'an 'vožo ärasaatmine' või jö villin sịlon 'jää peal seismine'. Ööl vastu 6. jaanuari käisid külanoored lauldes saunast sauna, "kuulasid saatust" ja ütlesid vožole: pot tatiś mil'emestịleś! 'mine siit meie juurest ära'. 6. jaanuari hommikul läksid mehed, kirved ja kaikad käes, jõele ning karjusid jääd tagudes: koški tattiśs! 'lahku siit' (Pervuhhin 1888b: 105-106). Mõnes bessermani külas kutsuti vožosid sellise rituaali ajal suvel tagasi head viljasaaki tooma (Popova 2004a: 126).

\section{Sümmeetriline liminaalsus udmurdi rahvakalendris}

Permi ja obi-ugri rahvaste mütoloogiates toimub ühendus meie maailma ja surnute maa (allilma) vahel peamiselt jõgesid mööda. Allavoolu liikumine tähendab ühtlasi allilma poole minemist ja vastupidi. Mansid nimetavad seda 


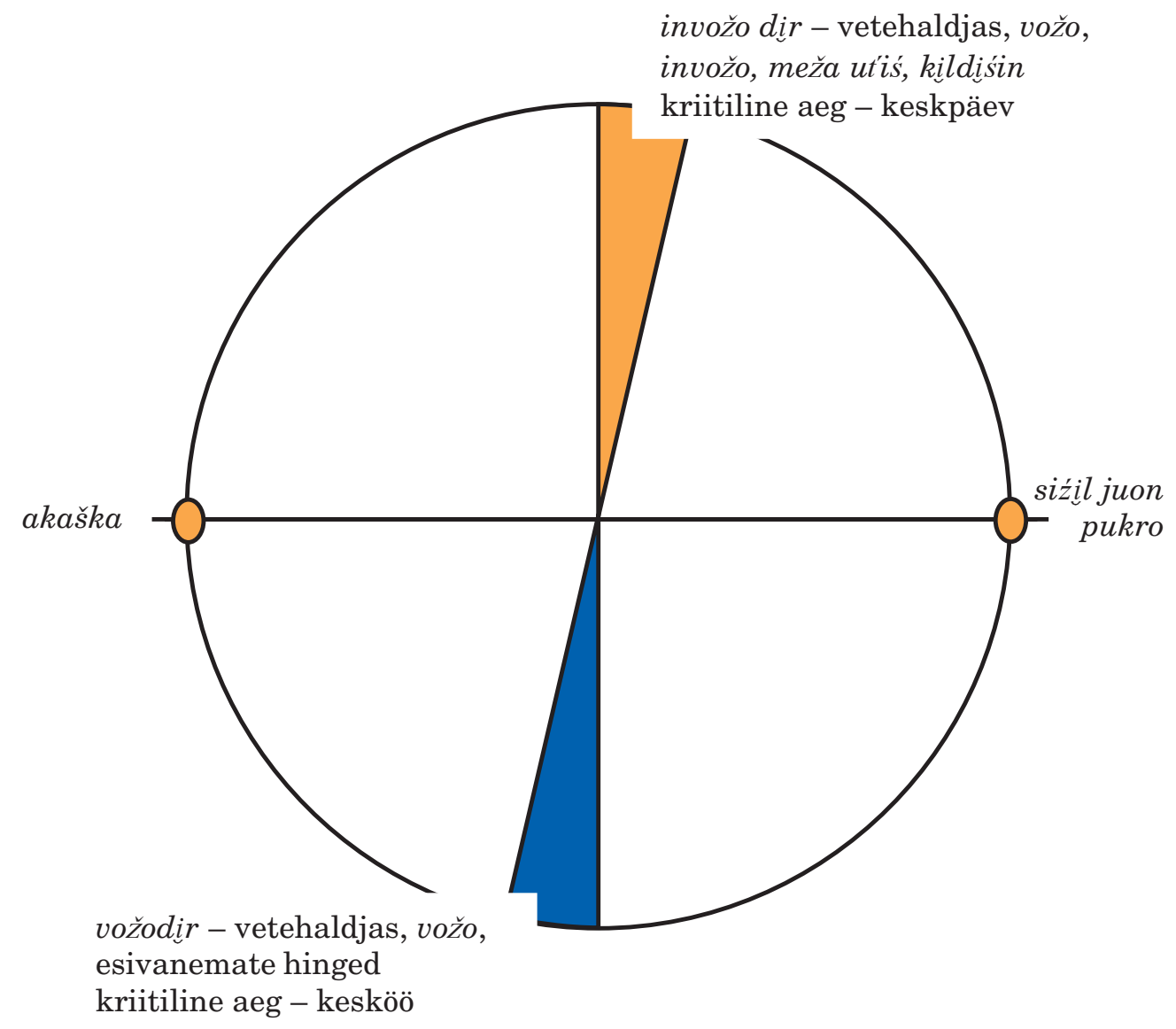

Joonis 1. Udmurdi rahvakalendri liminaalsed perioodid.

hingekomponenti, kes pärast inimese surma keha maha jätab ja surnute maale läheb, lonhal' minne is 'allavoolu minev hing'. Vetehaldjad, kes sageli olid demoniseerunud, seostusid allilmaga (vrd. mansi vitkas 'vetevaim', komi kul' 'kurat', vasa 'vetevaim', vakul' 'veekurat'. Udmurdi mütoloogilises geograafias tähendas 'allavoolu' (šur ullań) samuti 'allilma suunas'. Nii võime järeldada, et talvine vožo-periood oli otseselt seotud surnud esivanemate ja allilma kurjade vaimudega, kes olid eriti aktiivsed öösel (vrd uivožo 'öövožo'). Ööpäeva kriitilisim aeg oli kesköö.

Suvine invož-aeg oli aga ühenduses taevaga. Selle vältel kehtivaid piiranguid püüti järgida eriti keskpäeva paiku, kui inimesed püüdsid mitte kolistada ega lärmata. Mõnel pool nimetati invožod keskpäevavaimuks. Komi mütoloogias seostub suvine pööriaeg pölödnitsa-nimelise tegelasega, 
kes on ilmselt ühenduses vene keskpäevahaldjaga полудница. See üleloomulik olend elas või kõndis rukkipõllul ja oli eriti aktiivne rukki õitsemise ajal (Holmberg 1914: 175). On huvitav, et vene иолудница - valgeis rõivais naine - sundis inimesi endaga mõistatamises võistlema ja kõdistas kaotaja surnuks. Eespool mainisin, et üks mõistatuse rahvapäraseid termineid udmurtidel on vožo kỉl või vožo mad' (vožo sõna, keel või jutt). Samuti esitasin ütluse, et suvisel pööriajal kõnnib palve (usk) mööda niitu. Eksisteeris uskumus, et sel ajal jalutab üks udmurtide tähtsamaid jumalusi kildiśsin mööda rukkipõlde ja kaitseb küpsevat vilja. Rohkem tuntakse viljapõllu kaitsevaimu siiski nime all meža ut'is' 'põllupeenra hoidja'. Erinevalt vene keskpäevahaldjast kujutati teda ette valgeid rõivaid kandva mehena. Siinjuures tuleb märkida, et slaavi poludnica, polednice on väga lähedane vetehaldjaga. Polesjes oli vetehaldja üheks nimeks poludenik 'keskpäevavaim' (Levkijevskaja 1995: 339).

Mõnede arvates kestab suvine liminaalne periood isegi kuni 14. augustini ja lõpeb pühaga, mille nimi on vu villin sịlon ('vee peal seismine', vrd vastava talvise tähtpäevaga jää peal seismine). Bessermani Junda külast on kogutud järgmine teade:

Kristuse äraseletamise pühal, siis saadetakse vožo vette. See juhtub suvel. Sel päeval ujutakse viimast korda. Papp kastab risti vette. Vožod on juba ära läinud (Popova 2004b: 113).

Suvisel vožo-ajal kehtisid bessermanidel samasugused keelud kui udmurtidelgi:

Suvel oli ka vožo, ei tohtinud päeval pesu pesta, tohtis ainult varahommikul ja õhtul. Kardeti, et rahe peksab vilja maha (Popova 2004b: 114).

Vett ammutati jõest ainult tohtanumate või puupangedega. Jõgede ja allikate juures püüti mitte kära teha ning mitte kasutada musti nõusid (Popova 2004b: 114).

\section{Kokkuvõtteks}

Esitatud materjalist ilmneb, et udmurdi rahvakalendris on kaks sümmeetrilist liminaalset perioodi. Mõlemate nimed tulenevad liminaalsust või vahepealset tähistanud sõnast. Need perioodid erinevad oluliselt kevadise ja sügisese pööripäevaga seotud pühadest - nad on märkimisväärsel määral seotud veega, nende ajal kehtib käratsemise keeld. 
Kevadpüha akaška jaoks seevastu on iseloomulikud vali rituaalne laul, ratsutamine ja kiikumine. Mõnel pool toimuvad sel ajal ka poiste ja tüdrukute täisikka jõudmise riitused. Sügisest püha siźil juon ehk pukro saadab samuti vali laul, lisaks tantsitakse kõvasti jalgu trampides. Ei sügisene ega kevadine pööriaeg ei ole välja venitatud pikaks üleminekuperioodiks, vaid markeeritud konkreetsete kalendritähtpäevadega, mis on ühtlasi talvise ja kevadise poolaasta alguspunktideks. Liminaalsed ajad on seevastu pikad pühad perioodid, mida iseloomustavad ranged käitumiseeskirjad. Tõenäoliselt oli suvine liminaalne periood algselt pühendatud taevale (ülailmale) ja talvine liminaalne periood allilmale (surnute maale). Levinud oli ettekujutus, et pärast talvist vožo-aega lahkusid kõik vožod allavoolu.

\section{Kommentaarid}

${ }^{1}$ Vene folkloorist leiame motiivi näkkide põllul kõndimisest rukki õitsemise ajal (Krinitšnaja 1994: 23).

${ }^{2}$ vöś tähendab udmurdi keeles nii palvet ja ohvrit kui ka usku ja religiooni.

${ }^{3}$ Mõistatuse kohta käiv etniline žanrinimetus vožo mad' on ära toodud Boris Gavrilovil (1880: 54), Nikolai Pervuhhinil (1888c: 70) ja Yrjö Wichmannil (1901: 6-7). N. Pervuhhinil tähistab sama mõiste ka muinasjuttu. Tänapäeval on enimkäibivad omakeelsed terminid mõistatuse kohta mad'iśkon kil ja madkill.

4 19. jaanuari nimetati Põhja-Udmurtias vožo kel'an (vožo ärasaatmine) või jö villin sîlon / sulton (jää peal seismine).

\section{Kirjandus}

Gavrilov 1880 = Гаврилов, Борис Т. Произведения народной словесности, обрядв и поверья вотяков Казанской и Вятской губерний. Казань: Издательство Православнаго миссионерскаго общества.

Gribova 1975 = Грибова, Любовь С. Перлский зъериныци стиль (проблель селантики). Москва: Наука.

Holmberg (= Harva), Uno 1914. Permalaisten uskonto. Suomensuvun uskonnot 4. Suomalaisen Kirjallisuuden Seuran toimituksia 137. Porvoo: WSOY 1914.

Krinitšnaja 1994 = Криничная, Неонила А. На синел калне: Мифоловические рассказы и поверья о духе-кххозяинеђ bоды. Петрозаводск: Институт языка, литературы и истории Карельского научного центра РАН.

Levkijevskaja 1995 = Левкиевская, Елена Е. Комментарий 12 к гл. 5. Зеленин, Дмитрий Константинович. Избранные труды: Очерки русской мифологии: У иериие неестественною слертью и русалки. Традиционная духовная культура славян: Из истории изучения. Москва: Индрик, lk 339. 
Lintrop, Aado 2004. On the Udmurt Water Spirit and the Formation of the Concept 'Holy' among Permian Peoples. Folklore: An Electronic Journal of Folklore 26, 1k 7-26 (http://www.folklore.ee/folklore/vol26/lintrop.pdf - 5. september 2006).

Lõtkin 1952 = Лыткин, Василий И. Древнеперлский язык: чтение текстов, гралматика, словарь. Москва: Издательство Академии Наук СССР.

Nurijeva 2004 = Нуриева, Ирина Муртазовна. Удмуртская традиционная музыка и мифология. Владыкин, Владимир Е. (toim). удлуртская мифология. Ижевск: Удмуртский институт истории, языка и литературы Уральского отделения Российской академии наук, $1 \mathrm{k}$ 67-83.

Pervuhhin 1888a = Первухин, Николай Г. (koost). Эскизы иреданий и бьтта инородиеб Глазовского уезда 1: Древняя религия вотяков по её следал В совреленньхх преданиях. Вятка: Издательство Губерн. Стат. Ком.

Pervuhhin $1888 \mathrm{~b}=$ Первухин, Николай Г. (koost). Эскизы преданий и быта инородиев Глазовского уезда 2: Идоложертвенньй ритуал древних вотяков по его следал $b$ рассказах стариков и в совреленных обрядах. Вятка: Издательство Губерн. Стат. Ком.

Pervuhhin 1888c = Первухин, Николай Г. (koost). Эскизы преданий и быта инородиев Глазовского уезда 3: Следи язической древности в образиах произведений устной народной поэзии вотяков (лирических и дидактических). Вятка: Издательство Губерн. Стат. Ком.

Popova 2004a = Попова, Елена В. Время как одна из категорий традиционной модели мира бесермян. Владыкин, Владимир Е. (toim). Удиүртская мифология. Ижевск: Удмуртский институт истории, языка и литературы Уральского отделения Российской академии наук, lk 120-134.

Popova 2004b = Попова, Елена В. Календарные обряды бесерлян. Ижевск: Удмуртский институт истории, языка и литературы Уральского отделения Российской академии наук.

Puhvel, Martin 1989. The Crossroads in Folklore and Myth. American University Studies 4. English Language and Literature 88. New York: Lang.

Škljajev 1989 = Шкляев, Георгий К. Обряды и поверья удмуртов, связанные с жилищем. Владыкина, Татьяна Г. \& Христолюбова, Людмила С. (koost \& toim). Фольклор и этнография удмуртов: Обрядь, обьчаи, поверья. Ижевск: Удмуртский институт истории, языка и литературы Уральского отделения Академии наук CCCP, lk 28-43.

SKES 5 = Itkonen, Erkki \& Joki, Aulis J. \& Peltola, Reino 1975. Suomen kielen etymologinen sanakirja 5. Lexica Societetis Fenno-Ugricae 12: 5. Helsinki: Suomalaisugrilainen Seura.

Vladõkin 1994 = Владыкин, Владимир Е. Реливиозно-лифологическал картина лира удлуртов. Ижевск: Удмуртия.

Vladõkina 1998 = Владыкина, Татьяна Г. Удлуртский фольклор: Проблель жанровой эволюиии и систелатики. Ижевск: Удмуртский институт истории, языка и литературы Уральского отделения Российской академии наук. 
Wichmann, Yrjö Jooseppi 1901. Wotjakische Chrestomatie mit Glossar. Hilfsmittel für das Studium der finnisch-ugrischen Sprachen = Apuneuvoja suomalais-ugrilaisten kielten opintoja varten 2. Helsingfors: Finnische Literaturgesellschaft.

\section{Summary}

\section{Liminal Periods in the Udmurt Ritual Year}

Aado Lintrop

Key words: equinox, folk calendar, folk religion, liminality, Udmurts

On the example of the Udmurt material we can see that there are two symmetrical liminal periods in the Udmurt folk calendar. Both their names are etymologically derived from the word associated with liminality, existing somewhere in-between. These periods differ considerably from spring and autumn equinoctial times - there is remarkable connection with water, taboo against making noise, etc. Spring festivity akashka is celebrated by loud ritual singing, horseback riding and swinging. In some places they involve initiation rites - prayers by the boys and girls reaching full maturity. Autumn festivities siz'yl iuon and/or pukro are also accompanied by loud singing and making noise during dancing. Spring and autumn equinoctial times were not expanded into long periods, but were marked with specific festivities. They were the starting points for summer and winter halves of the year. Liminal times, conversely, were long sacred periods with severe restrictions. It is probable that the summer liminal period was originally dedicated to the heaven (upper world) and winter liminal period to the underworld (land of the dead). It was quite usual belief that after the winter vozhoperiod all vozhos went downstream. See also Lintrop, Aado. Liminal Periods in the Udmurt Ritual Year. Mifsud-Chircop, George (ed.). First International Conference of the SIEF Working Group on the Ritual Year: Proceedings: Malta, March 20-24, 2005. Publishers Enterprises Group, 2005, pp. 363-372. 